\title{
RASCUNHOS DA HISTÓRIA DA LEITURA ESCOLAR: ENTRE PORTUGAL E BRASIL*
}

\author{
Carlota Boto ${ }^{1}$
}

\begin{abstract}
RESUMO: Este artigo teve por objetivo a reconstituição de práticas escolares com base em um inventário de livros de primeira leitura e cartilhas elaboradas em Portugal e no Brasil, entre o fim do século XIX e o princípio do século XX. A hipótese que organizou esta pesquisa foi a de que os livros que ensinavam a ler e a escrever - além de ensinar saberes, talvez antes mesmo de ensinar saberes - pretendiam ensinar códigos de bom comportamento. $\mathrm{O}$ trabalho em tela propóe-se a verificar, por meio do estudo de manuais de ensino da leitura em Portugal e no Brasil, como aparecia, nos registros textuais, essa dimensão civilizatória intrínseca à escolarização. Para tanto, o diálogo teórico deu-se com a literatura educacional acerca de livros didáticos; e a metodologia adotada foi a investigação documental, especificamente centrada no estudo dos livros escolares.
\end{abstract}

Palavras-chave: Escola primária. História da educação. Rito. Livro didático. Compêndios escolares.

\section{DRAFTS OF SCHOOL READING HISTORY: BETWEen PORTUgal AND BRAZIL}

\begin{abstract}
The purpose of this paper was to reconstitute school practices based on an inventory of early primary reading books and booklets made in Portugal and Brazil between the end of the 19th and beginning of the 20th century. The hypothesis that led this research was that the books that taught reading and writing - besides teaching knowledge, perhaps even before teaching knowledge - were intended to teach codes of good behavior. This work proposes to verify, through the study of reading manualsin Portugal and Brazil, how this civilizational dimension intrinsic to schooling appeared in textual records. For that, there shall be a theoretical dialogue with the educational literature regarding textbooks, and the methodology adopted is documentary research, specifically focused on the study of school books.
\end{abstract}

Keywords: Primaryschool.Educationhistory. Rite. Textbook. School compendiums.

\footnotetext{
* O presente artigo é fruto de uma pesquisa pontual, desenvolvida junto à Faculdade de Educaçáo da USP, sobre a história dos livros didáticos de alfabetização e primeira leitura em Portugal e no Brasil (séculos XIX e XX) ${ }^{1}$ Universidade de São Paulo, Faculdade de Educação - São Paulo (SP), Brasil. E-mail: reisboto@usp.br DOI: 10.1590/ES0101-73302019211242
} 


\title{
BORRADORES DE LA HISTORIA DE LA LECTURA ESCOLAR: ENTRE PORTUGAL Y BRASIL
}

\begin{abstract}
RESUMEN: Este artículo tuvo por objetivo a reconstitución de prácticas escolares a partir de un inventario de libros de primera lectura y cartillas elaboradas en Portugal y en Brasil, entre fines del siglo XIX y el principio del siglo XX. La hipótesis que organizo ese estudio fue la de que los libros que enseñaban a leer y a escribir — además de enseñar saberes, tal vez antes incluso de enseñar saberes — pretendían enseñar códigos de buen comportamiento. El trabajo en lienzo se propone a verificar, por medio del estudio de manuales de enseñanza de la lectura en Portugal y en Brasil, como aparecía, en los registros textuales, esa dimensión civilizatoria intrínseca a la escolarización. Para tal, el diálogo teórico será con la literatura educacional acerca de libros didácticos; y la metodología adoptada es la investigación documental, específicamente centrada en el estudio de los libros escolares.
\end{abstract}

Palabras clave: Escuela primaria. Historia de la educación. Rito. Libro didáctico. Compendios escolares.

\section{Introdução}

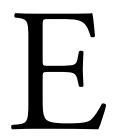

ste estudo teve por objetivo a reconstituição de práticas escolares a partir de um inventário de livros de primeira leitura e cartilhas elaboradas em Portugal e no Brasil, entre o final do século XIX e o princípio do século $\mathrm{XX}$. A hipótese que organizou esta pesquisa foi a de que os livros que ensinavam a ler e a escrever - além de ensinar saberes, talvez antes mesmo de ensinar saberes - pretendiam ensinar códigos de bom comportamento. $\mathrm{O}$ trabalho em tela propóe-se a verificar, por meio do estudo de manuais de ensino da leitura em Portugal e no Brasil, como aparecia, nos registros textuais, essa dimensão civilizatória intrínseca à escolarização. Para tanto, o diálogo teórico será com a literatura educacional acerca de livros didáticos; e a metodologia adotada é a investigação documental, especificamente centrada no estudo dos livros escolares.

O roteiro da civilidade escolar supóe o aprendizado dos valores, das atitudes, dos modos de estar diante do outro e das próprias maneiras de acessar os registros da língua. Aprender na escola significa, em alguma medida, aprender a falar corretamente, na contramão do que se caracterizava na época como falares regionais. Observa-se que a cultura que a escola produz estabelece, mediante o recurso dos livros didáticos e de outros utensílios escolares, a configuração de ritos, que compóem o dia a dia da sala de aula.

$\mathrm{O}$ rito de passagem rompe com a vida cotidiana. Instaura, por assim dizer, uma nova dimensão de tempo e de espaço. Há códigos e sinais que precisam ser, pelos atores, compreendidos nessa nova repartição do tempo. A função ritual 
da escola é dada por seus protocolos: pela maneira como os alunos são instados a agir, pela orquestração coletiva da ideia de classe, pela lógica simultânea a qual tende o ensino. A escola instaura sua vida cotidiana por meio de ritos, mediante os quais todos os seus atores serão convocados a agir.

A leitura na escola é um tipo de leitura muito específico. Antes de tudo, é uma leitura compartilhada. É, muitas vezes, uma leitura em voz alta. E, como dizem Chartier e Hébrard (1989), é também uma leitura explicada. Isso significa que ler na classe é uma tarefa repartida, que requer não apenas os olhos e a atenção, mas os olhos, o ouvido e a atenção. Os processos mediante os quais se processa a atividade da leitura constituem verdadeiros rituais que manifestam boa parte do repertório da escola, bem como o que poderíamos compreender por moral escolar. A multiplicidade das interaçóes humanas que integram a vida escolar é, por si, traduzida pela materialidade de seus produtos culturais tipificados pelo uso por classes: é este o caso do livro didático (Mathieson; Mortatti).

O livro é o terceiro personagem da escola, perdendo apenas para o aluno e o professor. O professor tem na vida institucional o lugar de representante institucional da cultura elaborada. Por ser assim, ele se impóe, em sala de aula, como mediador entre o aluno e o livro. Mesmo assim, no desenrolar do cotidiano da instituição, muitas vezes parece que o livro é que se arvora o direito de ser mediador entre aluno e professor. De qualquer modo, são tempos e espaços simbólicos, políticos, sociais e pedagógicos, que, todavia, traduzem-se também pela materialidade da arquitetura, dos objetos de sala de aula, dos utensílios das classes.

O livro que circula, por seu turno, deverá também ser enquadrado. Por não ser mais possível controlar a circulação do impresso, torna-se imprescindível controlar sua leitura: e a mesma escola que ensina o ler e o escrever servirá para também adestrar o gesto leitor. Mas a sociedade que se vale do escrito para ensinar a criança, vale-se do escrito para ensinar o professor a ensinar a criança. Circe Bittencourt (1993) observa que a produção de manuais didáticos surge historicamente com o objetivo de acolher necessidades didáticas do professor. Trata-se de um guia norteador de conteúdos e de métodos; um plano que deverá organizar a produção da aula.

\section{O livro didático como objeto cultural}

Na segunda metade do século XIX, existirá no Brasil, como em Portugal, por parte do debate pedagógico em circulação, uma tendência a se incentivar a produçáo nacional de livros escolares; com o fito de estruturar um projeto de nacionalização necessário à escola pátria. Os conteúdos dos livros escolares destinados ao ensino da leitura e da escrita — fossem cartilhas, voltadas para o primeiro nível da alfabetização, fossem livros de leitura - eram apresentados, a um só tempo, como fatores de civilizaçáo e de conhecimento. 
O estudo desse material é o típico movimento da articulação entre a história e a filosofia da educação. É um estudo em história porque trabalha vestígios do passado e a reconstituição da trajetória escolar a partir de documentos; e é filosofia da educação, posto que as fontes abordadas indicam vetores de ensino e formas de aprendizado que eram valorizadas em seu tempo e que constituíram, em alguma medida, nosso modo escolar de civilizar.

Como adverte Kazumi Munakata (1999), o livro didático é um objeto cultural com o qual historicamente o leitor dialoga: pelo diário manuseio, por registros e anotaçóes nas bordas, por rabiscos e sinais... O uso do livro didático tem uma configuração singular. A produção e a editoração do livro evidenciam a ambiguidade da condição do leitor que virtualmente aguarda o produto impresso. O livro didático é dirigido tanto ao professor quanto ao aluno. Pensando no leitor-professor, o livro deve conter protocolos de leitura que explicitem roteiros de ação prescritivos de práticas de sala de aula. Por prefácios, por textos de apresentação, por introduçóes e por entrelinhas, enquanto didático, o livro deve ensinar a ensinar.

$\mathrm{Na}$ outra margem, atento também ao aluno-leitor, caberá a esse compêndio de leitura escolar transmitir recomendaçóes que indiquem claramente maneiras adequadas de se ler: em primeiro lugar, tratava-se de "disciplinar o olhar segundo uma linearidade cartesiana - lê-se horizontalmente e, depois, verticalmente - e abstrair eventuais informaçóes extratextuais - como a numeração da página” (MUNAKATA, 1999, p. 584). Nesse sentido, há toda uma pedagogia dos procedimentos de leitura que envolve algum nível de regulaçáo do próprio manuseio do material impresso. Ensinar a ler abarca, por suposto, o conteúdo da palavra lida, mas implica também procedimentos de forma que deverão ser assimilados como requisito à própria assimilação do texto.

As cerimônias de uso do livro didático supóem um formato de escolarização no qual o ensino é simultâneo. Neste, o professor falará com todos os seus alunos como se eles, reunidos, fossem apenas um só. $\mathrm{O}$ método da exposição, da lição magistral com que o mestre apresenta o conhecimento, estrutura uma forma de agir que supóe indistintos, entre os alunos, os padróes e os ritmos de aprendizagem.

O moderno modelo de escola, que tomará o livro didático como instrumento fundamental, terá a unidade da estrutura da aula como pilar fundador dos princípios de gradação de conteúdos e matérias que regularão o aprendizado. Junto com o livro adotado pela escola, "a graduação escolar e a classificação dos alunos aparecem como dispositivos claros para a organização pedagógica da escola primária baseada na divisão dos alunos em seçóes e por graus de instrução" (SOUZA, 1998, p. 40).

Investigar o lugar social do aprendizado da leitura requer alguma meditaçáo sobre os requisitos de formação em uma sociedade pautada pela cultura impressa; uma sociedade dominada por uma comunidade de leitores. Escolarizar a infância e a juventude — como bem avalia Ana Maria de Oliveira Galvão - era, "de um lado, pro- 
porcionar a incorporação de novos comportamentos; de outro, provocar o abandono de costumes vividos no mundo familiar: essa era a dupla tarefa da escola" (GALVÃO, 1998, p. 120). Mais do que isso, urgia, por meio da escola, compor uma formação social urbana e industrial, hábil para projetar o país para alçar os níveis de ilustração e de cientificidade das naçóes tidas por avançadas no Ocidente. A forma do escrito era, para isso, um requisito; uma condição. A escola primária, ao desenvolver a habilidade leitora, indicava o progresso da sociedade futura. Acerca do tema, Diana Vidal destaca:

Ler rápida e eficazmente, decifrando com velocidade os signos escritos era, e continua sendo, uma das necessidades da sociedade moderna, em que a apreensão veloz da mensagem escrita torna-se a única maneira de lidar com a profusão de impressos em circulaçáo e com a proliferação de escritas que demarcam os usos nos universos social, urbano e do trabalho. Constituir leitores era, assim, [...] produzir decifradores de uma cultura urbana cada vez mais associada a signos escritos; de uma cultura do trabalho relacionada com informes e manuais e de uma cultura social caracterizada pela profusão de informaçóes (VIDAL, 1999, p. 353).

\section{O ensino simultâneo como novo método de aprender a ler com rapidez}

A busca do ensino simultâneo era uma característica dos compêndios de pri-
meira leitura desde, pelo menos, meados do século XIX. É o que se percebe quando se lê a obra didática de J. I. Roquet (1862), autor de Alphabeto portuguez ou novo methodo para aprender a ler com muita facilidade e em muito pouco tempo tanto a letra redonda como a manuscripta - publicada, pela edição aqui localizada, no Rio de Janeiro de 1862 - obra com trechos escritos e imagens praticamente idênticos aos encontrados no compêndio de ensino da primeita leitura, de autoria de Emílio Achiles Monteverde (1859), intitulado também, significativamente, Methodo facillimo para aprender a ler tanto a letra redonda como a manuscrita no mais curto espaço de tempo, cuja $7^{\text {a }}$ ediçáo foi publicada em Lisboa pela Imprensa Nacional, em 1859 (DAMIÃO, 2006) ${ }^{1}$.

Em Roquet, como em Monteverde, há a orientação ao professor, pelo indicativo dado a propósito do que se considerava ser a superioridade do modo simultâneo de ensino, frente ao individual e até ao modelo de ensino mútuo. Tanto em Portugal (BOTO, 1997) como no Brasil (GALLEGO, 2011), foi entre os anos 60 e 70 do século XIX que o ensino simultâneo ganhou corpo nas práticas escolares, embora as prescriçóes nesse sentido fossem bastante anteriores.

Nos termos de Roquet:

O ensino simultâneo consiste em dividir os discípulos em diversas classes ou turnos, segundo as suas forças, e fazer seguir 
ao mesmo tempo a toda uma classe a mesma lição de leitura, escrita, cálculo, etc., isto é, o professor manda ler a cada um em voz alta, e os outros o váo seguindo em seus livros ou cadernos. O professor passa sucessivamente de uma a outra classe, tendo todo o cuidado em que estejam empregadas em alguma coisa aquelas a que náo assiste nesse intervalo. As crianças, achandose constantemente em presença umas das outras, estimulam-se reciprocamente, e aproveitam a lição (ROQUET, 1862, p. 5-6).

A preocupaçáo com o falar corretamente a língua aparece em muitos dos livros de leitura consultados. José Feliciano de Castilho Barreto e Noronha, em livro dedicado ao Imperador Pedro II, sob o título Iris clássico coordenado e oferecido aos mestres e aos alunos das escolas brasileiras, publicado em 1873 no Rio de Janeiro, discorria exatamente sobre o caráter mutável das línguas, que crescem, ampliam-se e se modificam; razão que torna ainda mais necessário o cuidado que se deve ter para preservar sua estrutura. É necessário cuidar do aprendizado da língua materna para que ela possa se ampliar e se enriquecer, sem, todavia, desfigurar-se por "mudança precipitada, violenta, caprichosa e irrefletida ou néscia" (NORONHA, 1873, p. 8). Diz o autor sobre o assunto:

Que os idiomas, com o rodear dos anos, se metarmofoseiam, se encorpam e acompanham por seus passos contados a civilização, verdade é essa que a história dos povos nos confirma: que todos os idiomas propendem, como dizíamos, para a mútua assimilação, também a observação no-lo ensina; e que, bom ou malgrado de quem quer que for, o dia em que todos os homens sem intérprete se entendessem, seria a véspera de uma espécie de paz universal (NORONHA, 1873, p. 7).

Felisberto de Carvalho (1926) é bastante explícito na orientação que dá aos professores sobre os modos de se ensinar a língua portuguesa. Em seu primeiro livro de leitura, datado de 1892, o autor destaca com exatidáo a liturgia pela qual se deverá processar o ensino paralelo da leitura e da escrita. Ensinar a ler é ensinar a pensar de outra maneira. Mas requer também o aprendizado de modos de comportamento diferentes. O controle do corpo exigido pela leitura, por exemplo, convida a exercitar a imobilidade necessária à caligrafia. $\mathrm{O}$ ato da leitura deverá ser entrelaçado com o exercício da caligrafia e com a prática da ortografia. Para o professor "distribuir seu tempo", é imprescindível como indica o excerto abaixo - manter os alunos ao mesmo tempo calados e ocupados.

A forma da leitura escolar, expressa pelo ritual de uma leitura alternada entre os alunos, constitui alicerce do processo da alfabetização. Aprender a ler e a escrever é também aprender a ler com fluência. Todos os alunos da classe deverão ler um trecho juntos; depois lerão um a um — ao sinal dado pelo professor. Tais leituras são marcadas por um ritmo todo próprio; mas possuem também outro componente a ser registrado: o componente da moralização. Os livros de leitura da escola primá- 
ria primam por trazerem exemplos: de mérito deste ou daquele personagem, de boas açôes e das próprias narrativas, argutamente construídas como elencos exemplares de atitudes tidas por adequadas. A leitura da escola primária constitui, nesse sentido, uma das mais efetivas estratégias do que temos chamado de civilização escolar.

\section{A classe e o ritual da sala de aula}

No Segundo livro de leitura, editado em Petrópolis pelos professores da Escola Gratuita São José, em sua 9a ediçâo com data de 1922, em estilo pelo qual o aprendizado da leitura vem pelo ensino de graciosas narrativas, pode-se ler a história de Paulo. $\mathrm{O}$ menino Paulo chegava sempre tarde na escola. Nunca estava na classe no horário. Suas notas eram más. O professor julgava que o menino era incorrigível. A leitura explica a Paulo e aos leitores como deve ser a saída do colégio:

Quando vocês saírem do colégio, depois das aulas, meus amiguinhos, conduzam-se como meninos bem educados. Não façam como tantos outros meninos, que percorrem as ruas em grupos, aos empurróes, aos gritos, às gargalhadas. Há alguns que levam mais longe sua falta de educação, provocam os que passam, náo respeitam os velhos, escarnecem dos pobres e dos enfermos. Oh! Como isso é feio! Nunca procurem imitar esses meninos maus e grosseiros (SEGUNDO LIVRO..., 1922, p. 33).

O cenário da classe é um aspecto bastante importante, que possibilita a compreensão da escola como um rito. O palco se dispóe para que a peça seja, todos os dias, ensaiada. Todos os dias - no mesmo tablado - tem lugar a liturgia do aprendizado da leitura, da escrita e do cálculo. No limite, é isso que se aprende no primeiro degrau da escolarização. Mais do que isso, talvez, seja o aprendizado do bom comportamento civil. Esse também constituía matéria a ser perfilhada na escola primária.

Ulysses Machado, em Portugal, no Livro de leitura para a segunda classe do ensino primário geral, destaca claramente qual deveria ser o modelo do ritual escolar. E descreve esse modelo à luz do mobiliário previsto para a sala de aula e de seus usos. O texto que dá início ao referido compêndio, demonstra - de modo explícito - como o professor deve agir em sua classe. Além disso, a classe aparece, sob todos os pontos de vista, como o lugar por onde entra a luz:

Vou à escola. Cumprimento o senhor professor. Sento-me no meu lugar. Ponho a mala na minha carteira. O senhor professor está no seu lugar. Vai ao quadro preto. Escreve com o giz. Manda-nos preparar os nossos livros, os nossos cadernos e os nossos lápis. Começa a lição. A sala de nossa classe é espaçosa. Tem muitas janelas, por onde entram o ar e a luz. Os alunos, quando entram na classe, abrem e fecham a porta devagar. As paredes estão guarnecidas de quadros com estampas. O teto brilha 
como um espelho. Está pintado a óleo. O sobrado é de madeira. Está muito limpo. O senhor professor, do seu lugar, vê todos os alunos. As nossas carteiras são cômodas. $\mathrm{O}$ quadro preto faz parte do mobiliário escolar. É de ardósia. Nalgumas escolas é de madeira. O quadro preto é retangular. Está colocado num cavalete. Os alunos escrevem, desenham e fazem contas com giz no quadro preto. Algumas escolas têm dois e três quadros pretos pendurados na parede. O senhor professor também escreve e desenha no quadro preto. Devemos estar sempre atentos às explicaçóes que o senhor professor faz no quadro preto (MACHADO, 1922, p. 4).

Os livros dirigidos aos professores já deixavam claro que os materiais de ensino e os próprios utensílios de sala de aula são fundamentais. $\mathrm{O}$ trabalho de Marta Carvalho constatou que os materiais utilizados para o ensino estáo nessa literatura intrinsecamente vinculados aos métodos, aos modos de ensinar e à própria pedagogia, o que, por sua vez, incita ao domínio de práticas, estabelecidas como "boa imitação de um modelo" (CARVALHO, 2006, p. 147). Também nos livros de leitura das crianças há esse vínculo estabelecido entre o ensino bem-sucedido e a "forma da escolarização".

O rito da escola primária, no argumento de Ulisses Machado, será tão melhor desempenhado quanto forem adequados os materiais, o mobiliário da sala de aula e os utensílios didáticos, como livros e cadernos. As rotinas da classe são formas de interagir com o trabalho escolar. Compreende-se que os materiais escolares possuem uma função simbólica bastante específica, fazendo por recordar às crianças que, como escolares que são, elas deverão deixar a espontaneidade da infância para adquirirem uma segunda pele, expressa na condição de alunos. Os objetos dos alunos são, nesse sentido, também fundamentais.

Quando vou para a escola, levo na minha mala os livros, os cadernos, a caneta, a pena, o lápis, a régua, a ardósia, a pena de pedra e a esponja. Os livros e os cadernos são de papel. Os livros são impressos; os cadernos sáo manuscritos. A régua é de madeira. Comprei os livros na livraria. Comprei os cadernos e os outros objetos na papelaria. A minha ardósia consta de duas partes: o caixilho e a pedra. O caixilho é de madeira. A pedra é preta. Tem uma das faces pautada de linhas vermelhas. Escrevo, desenho e faço contas na ardósia com a pena de pedra. Apago a escrita, o desenho e as contas com uma esponja molhada em água. As ardósias em que escrevemos são preparadas em fábricas especiais. $\mathrm{O}$ meu caderno consta de papel branco e de capa. O papel está pautado. A capa é amarela. O meu caderno está cosido com linha branca. É retangular. Sirvo-me do caderno para escrever, desenhar e fazer contas. Tenho o meu caderno asseado. Os cadernos vendem-se nas papelarias (MACHADO, 1922, p. 5-6).

A ideia de leitura corrente passa pela noção de leitura instrutiva. Trata-se de aprender a ler, mas não se deverá ler qualquer coisa. O aprendizado 
escolar da leitura deve ser o aprendizado dos bons conteúdos impressos nos bons livros. Afinal, o que a escola ensina é o ler, o escrever, o contar, mas também o bom comportamento. Sendo assim, a tarefa do ato de ler pressupóe um movimento anterior de edição, recorte de seleção do que pudesse ser considerado leitura proveitosa. Por isso a escola tende a extrair da literatura os trechos seletos. Por isso o livro de leitura tende a recortar a leitura em pedaços. Por isso a leitura escolar frequentemente torna-se enfadonha.

Os livros didáticos indicam os rituais da escolarização. Mas, além de saberes, os livros veiculam também valores. Esses livros não ensinam apenas as coisas que dizem ensinar. Ensinam normas, regras, prescriçóes e procedimentos para orientar a conduta do aluno, com o fito de desenvolver atitudes e referências morais. É isso que aparece, por exemplo, na Grammática intuitiva da língua portuguesa, publicada em 1901, por Antonio Bastos, que era, à época, professor da Escola Normal de Lisboa. Os exemplos que o autor oferece para proceder à análise sintática indicam claramente maneiras subliminares de produzir no estudante atitudes de respeito e de obediência aos ritos escolares. Os ritos não admitem que se fuja ao roteiro prescrito. $\mathrm{E}$ a escola não foge a essa regra; nem mesmo quando ensina as regras da conjugação verbal:

Analise o seguinte: "eu desejo que estude". Temos aqui dois verbos: desejar, estudar. A flexão desejo do primeiro já nós sabemos que pertence ao presente; a flexão estude do segundo é que nós ainda não conhecemos. O presente, por nós já sabido, deste verbo é: estudo, estudas, etc. A flexáo, pois, que temos agora diante de nós - estude - não parece por isso presente; pretérito também não é, futuro ainda menos. Há então aqui alguma ilusão nossa. Vejamos: eu posso dizer: - desejo que estude agora, isto é, a flexão estude parece em tal caso (agora) indicar também presente. Existirão duas maneiras de indicar o tempo presente? Parece que sim. Quando eu digo estudo, indico com esta flexão (que é presente, visto que posso dizer estudo agora) um fato positivo, independente, geral; mas se disser quero que estude (que é também presente, porque posso dizer estude agora) indico um fato apenas possível, dependente, particular, subordinado à significação de outro verbo quero. Daqui se deve concluir que há duas maneiras ou modos diferentes de enunciar a significação do verbo. É claro que, quando digo duas, me refiro exclusivamente às duas maneiras que estamos a estudar, porque, como se verá, há mais (BASTOS, 1901, p. 71).

\section{O aprendizado da leitura como uma "forma escolar de civilização"}

No tocante ao ensino de História, é muito visível a maneira como são engendrados roteiros interpretativos voltados para a produção de visóes de mundo políticas. Como assinala Patrick Nerhot (1998, p. 96), "um passado é um transporte de sentido: 
a partir do momento em que se trata de enunciar o sentido (de um escrito, portanto, de um traço que já enuncia sentido), um passado é inferido". Para o autor, o passado inferido pelo traço não apenas é sentido, mas vem como testemunho, com a função de "atestar o presente" (NERHOT, 1998, p. 97). E por isso qualquer sentido sobre o passado recompóe significados, reinventando - a posteriori - uma "cadeia ininterrupta de significantes” (NERHOT, 1998, p. 98). O ensino de história tem, para isso, uma dimensão privilegiada, posto que ali se deverá compor um dado "sentimento de pertencer a uma comunidade" (BORNE, 1998, p. 139), o que inclui partilhar territórios e apreender um "sistema de imagens, de referências e de valores" (BORNE, 1998, p. 139). Como já nos ensinou o trabalho de Circe Bittencourt para o caso brasileiro (1993), a produçáo da memória no ensino de história é uma estratégia clara para estruturar visões de mundo consideradas oportunas para as camadas em posição de domínio no jogo social.

Civilizar o aluno rebelde passa também pela marca da postura; compreendido esse termo como atributo físico e espiritual. Existe, pois, uma postura física e uma postura moral. Compor o sujeito bem-comportado é também instruí-lo para que ele aprenda a se portar. Para se portar bem, há de se pensar no porte. A postura corporal, nesse sentido, torna-se indício do que se passa por dentro... Do corpo ao espírito, trata-se de conferir norma a uma população desregrada. Isso era o que pretendia fazer o compêndio intitulado Leitura manuscripta, texto provavelmente datado do início do século XX, que tinha por subtítulo liçóes colligidas por BPR. Não há, no exemplar que pudemos localizar, indicação do nome do autor, da data de edição ou da casa editora.

Não obstante, há o claro registro de que a obra havia sido aprovada para adoção pelas escolas públicas do estado de Sáo Paulo, pertencendo o exemplar à Biblioteca da Escola Normal de São Paulo, posterior Coleção Paulo Bourroul. Ao apresentar a necessidade da caligrafia, o autor demonstra claramente que o treino caligráfico é um motivo e um pretexto para adestrar os gestos, firmar a mão e conformar a postura física, em relação especificamente ao espaço da escola, mas também em relação ao lugar do outro. Nesse sentido, o diálogo sobre a caligrafia supostamente travado entre duas crianças — o menino Álvaro e sua irmã — evidencia o intuito:

- Não digas que estás adiantado na escola. Até é feio. Pois então esta letra é de um aluno adiantado? - Ora, tu pareces tola. Que é que vale a caligrafia? - Que é que vale? Minha mestra não me daria uma só nota boa se eu escrevesse assim. - Os mestres andam sempre com essas histórias. Diz-me uma coisa: que é que vale mais - a casca ou o miolo? A caligrafia é a casta e o miolo é o que a gente escreve, o sumo. - Sim, mas uma página de letra bem talhada, bem limpa, é uma coisa muito bonita. - E a tal baboseira de sempre. De que serve ser bonita? Melhor, muito melhor é que seja bem escrita, com correção e estilo elegante (LEITURA MANUSCRIPTA, s.d., p. 3-4).

Álvaro continua insistindo com sua irmã, agora a evocar o argumento de que grandes homens, incluindo os médicos, costumam ter letra feia. Nesse momen- 
to, chega o pai das duas crianças; e ele dá razão à menina. Sublinha que é, sim, necessário cuidar da caligrafia, como prova de boa educação e de civilidade. A civilidade, o pai define com as seguintes palavras: "em nossas relaçóes tanto familiares como sociais, devemos procurar sempre aquilo que for agradável às pessoas com quem tratamos e evitar tudo aquilo que possa ser desagradável" (LEITURA MANUSCRIPTA, s.d., p. 5). Nesse sentido, o pai das crianças recorda que é de bom tom vestir-se de maneira asseada, falar com cortesia, e (por que não?) escrever com elegância para "deixar uma impressão agradável” (LEITURA MANUSCRIPTA, s.d., p. 5).

O tema da civilidade perpassava - como já se viu —, além dos cadernos das crianças, os conteúdos dos compêndios de leitura elementar. Mas estava também presente nas revistas do magistério, ou nas revistas voltadas para a leitura instrutiva das crianças, como se verá em seguida.

A civilidade é — sem sombra de dúvida — um dos principais elementos contidos no processo de socializaçáo escolar. Mas essa civilidade, nos casos brasileiro e português, tem ainda a marca da fidalguia ou da distinção aristocrática. O discurso veiculado proclama a existência de hierarquias e degraus, com pessoas superiores e outras inferiores no tabuleiro social - cada uma devendo ser tratada de acordo com sua posição na hierarquia previamente estabelecida. Os livros das crianças recomendam que se deve dar, todavia, o tratamento justo e caridoso relativamente aos inferiores. Evidentemente, a distância entre adultos e crianças é uma das fronteiras que estabelece relaçôes de subordinação e dependência. Essa vem explícita quando as demais — de classe, de raça, de etnia, de gênero, de condição social — não são exatamente explicitadas. Especialmente no caso brasileiro, a recém-proclamada república não deixava de ser uma república de coronéis, cujo traço de mandonismo ainda imperava nas relaçóes sociais. E a criança será preparada para a sociedade que a espera. Daí o caráter conservador da civilidade prescrita pela escolarizaçáo.

A moral escolar é um elemento constitutivo dos próprios saberes da escola primária. Passava pela senda de ritos que não eram apenas os ritos inscritos nas prescriçóes. Não se trata de pensar apenas em como deveria funcionar a escola, mas nas coisas que de fato lá acontecem. Por exemplo, como age o professor quando há a falta de um aluno? No suplemento da revista pedagógica portuguesa Educação nacional, que abrigava o discurso republicano nos últimos anos da monarquia em Portugal, há algumas recomendaçóes acerca dos procedimentos adequados para serem tomados por professores:

Deveres para com os camaradas: a franqueza. - Lição - Há muitos meios de fazer mal aos condiscípulos. Enquanto o professor tem as costas voltadas, um aluno cantarolou. O professor ouviu. Pergunta quem trauteou. Ninguém responde. Os outros não o denunciam. Mas o culpado deve denunciar-se por si mesmo. Sem isso expóe todos os alunos a serem castigados. É um mal fazer o que é proibido, mas é pior não o confessar. É necessário ter coragem para reconhecer o erro feito, confessando-o. A franqueza do culpado dispóe de mais a mais a indulgência do professor (EDUCAÇÁO NACIONAL, 1899, p. 5-6). 


\section{Considerações finais}

Toda a documentaçáo consultada indica um modo de ser, correspondente à descrição do existente, e indica também - sob caráter normativo - uma dimensão por vir: ou seja, como deveria ser organizado o ritual escolar - com móveis, utensílios e métodos disponíveis e adequadamente mobilizados em uma rotina composta de invenção, mas, em alguma medida, sob a referência de um traçado previamente ordenado inscrito nas prescriçōes sugeridas em livros ou em revistas.

A liturgia escolar tem - digamos - alguns pressupostos: o primeiro deles deriva do lugar social ocupado pela escola, no que toca à intermediação da vida familiar e comunitária para a vida pública. A escola será, nesse sentido, a segunda instância de socializaçâo da criança. Ela acolhe o menino da família e o prepara para ingressar no mundo dos adultos. É preciso, portanto, ensaiar o roteiro desse mundo adulto; exercitar a convivência; ensinar parâmetros de conduta necessários para a vida em sociedade. Nesse sentido, desde logo, a escola se coloca como instância de formação: trata-se de cuidar e modelar; recolher e acolher; instruir e formar; ensinar e educar.

Por ser tudo isso, o rito da escola contempla em si alguma dureza. A escola deverá, por suposto mais do que a família, potencializar na criança o que há de melhor, de mais ousado em sua natureza. Para tanto, haverá de ser criada uma segunda natureza: a natureza da civilidade. Trata-se de transformar a civilidade "de potência em ato". Essa foi a hipótese que norteou a pesquisa e que foi ratificada pelo estudo da documentação consultada. O tempo da escola é visto como tempo de aprender os scripts indispensáveis à convivência: o aprendizado da tolerância, da espera, do adiamento da satisfaçấo, da "resistência à frustração", do controle de si e da generosidade perante o outro.

O exercício escolar contempla, portanto, o preparo da convivência social. E essa convivência implica todas as distinçôes colocadas em relação à distribuiçáo dos lugares sociais. Talvez por isso possa-se concluir afirmando que a escola, em seu lugar de instituição posta na esfera pública, constitui um ritual de passagem para o aprendizado da civilidade. Ontem como hoje, ir para a escola é aprender a conviver com o outro. Em uma época em que o homeschooling tem sido visto como alternativa, é importante registrar, pela pesquisa, o lugar de socialização ocupado pela vida escolar. Esse foi o objetivo que norteou a presente pesquisa.

\section{Notas}

1. Dalila Rodrigues Damião, em seu trabalho, efetuou "análise comparativa de Monteverde e Roquet" (DAMIÂO, 2006, p. 40). Seu trabalho defende a hipótese de que Roquet tenha se valido da estrutura e copiado, inclusive, trechos da cartilha de Monteverde. Damiáo conclui que "em Monteverde verificamos a originalidade, enquanto em Roquet o plágio" (DAMIÂO, 2006, p. 41). Damiáo dedica-se, nesse sentido, a averiguar a estrutura das duas obras, identificando, efetivamente, um conjunto excessivo de trechos idênticos ou similares. 


\section{Referências}

BASTOS, A. Grammática intuitiva da língua portuguesa. Porto: Livraria Editora de Antonio Figueirinhas, 1901.

BITTENCOURT, C. M. F. Livro didático e conhecimento histórico: uma história do saber escolar. 1993. Tese (Doutorado) - Universidade de São Paulo, São Paulo, 1993.

BORNE, D. Comunidade de memória e rigor crítico. In: BOUTIER, J.; JULIA, D. Passados recompostos: campos e canteiros da História. Rio de Janeiro: UFRJ/FGV, 1998. p. 133-141.

BOTO, C. J. M. C. dos R. Ler, escrever, contar e se comportar: a escola primária como rito do século XIX português (1820-1910). 1997. Tese (Doutorado) - Faculdade de Filosofia, Letras e Ciências Humanas, Universidade de São Paulo, São Paulo, 1997.

CARVALHO, F. de. Primeiro livro de leitura. 109. ed. Rio de Janeiro: Francisco Alves, 1926.

CARVALHO, M. M. C. Livros e revistas para professores: configuração material do impresso e circulação internacional de modelos pedagógicos. In: PINTASSILGO, J.; CARVALHO, M. M. C.; FREITAS, M. C.; MOGARRO, M. J. (Orgs.). História da Escola em Portugal e no Brasil. Circulação e apropriação de modelos culturais. Lisboa: Colibri/Centro de Investigação em Educação da Faculdade de Ciências da Universidade de Lisboa, 2006. p. 141-173.

CHARTIER, A.-M. Escola, culturas e saberes. In: XAVIER, L. N.; CARVALHO, M. M. C.; MENDONÇA, A. W.; CUNHA, J. L. (orgs.). Escola, culturas e saberes. Rio de Janeiro: FGV, 2005. p. 9-28.

CHARTIER, A.-M.; HÉBRARD, J. Discours sur la lecture (1880-1980). Paris: Centre George-Pompidou, 1989.

DAMIÃO, D. R. Cartilhas escolares e livros de primeiras leituras no Brasil dos séculos XIX e XX. 2006. Trabalho de Conclusão de Curso (Graduação) - Faculdade de Educação, Universidade de São Paulo, São Paulo, 2006.

EDUCAÇÃO NACIONAL: supplemento - discussões pedagógicas e exercícios práticos. $1^{\circ}$ de outubro de 1899 . v. 1.

GALLEGO, Rita de Cassia. A configuração temporal e as inovações nos modos de ensinar e aprender nas escolas públicas primárias (Sáo Paulo - Brasil - 1850 a 1890). In: PERANDONES, Pablo Celada. Arte y oficio de enseñar. Dos siglos de perpectiva histórica. El Burgo de Osma: Sociedad Española de Historia de la Educación / Universidad de Valladolid/ Centro Internacional de la cultura escolar, 2011. p.117-125.

GALVÃO, A. M. de O. A palmatória era a sua vara de condão: práticas escolares na Paraíba (1890-1920). In: FARIA FILHO, L. M. (org.). Modos de ler/Formas de escrever: estudos de história da leitura e da escrita no Brasil. Belo Horizonte: Autêntica, 1998. p. 117-142.

LEITURA MANUSCRIPTA: lições colligidas por B.P.R. aprovada para ser adotada em todas as escolas publicas do Estado. Exemplar pertencente à Biblioteca da Escola Normal de São Paulo. s.d. (Coleção Paulo Borroul). 
MACHADO, U. Livro de leitura para a segunda classe do ensino primário geral. Lisboa: Livraria Rodrigues, 1922.

MATHIESON, Louisa Campbell. Conversas sobre ler e escrever: alfabetizaçáo e cultura escolar na Revista de Ensino (1902-1910). Faculdade de Educação da Universidade de São Paulo: Trabalho Complementar de Curso, 2009.

MONTEVERDE, E. A. Methodo facillimo para aprender a ler tanto a letra redonda como a manuscrita no mais curto espaço de tempo. 7. ed. Lisboa: Imprensa Nacional, 1859.

MORTATTI, Maria do Rosário Longo. Os sentidos da alfabetização (1876/1994). São Paulo: Unesp, 2000

MUNAKATA, K. Livro didático: produção e leituras. In: ABREU, M. (org.). Leitura, história e história da leitura. Campinas: Mercado de Letras/Associação de Leitura do Brasil/Fapesp, 1999. p. 577-610.

NERHOT, P. No princípio era o Direito... In: BOUTIER, J.; JULIA, D. Passados recompostos: campos e canteiros da História. Rio de Janeiro: UFRJ/FGV, 1998. p. 91-103.

NORONHA, J. F. de C. B. Iris clássico coordenado e oferecido aos mestres e aos alunos das escolas brasileiras. 6. ed. Rio de Janeiro: Eduardo \& Henrique Laemmert, 1873.

ROQUET, J. I. Alphabeto portuguez ou novo methodo para aprender a ler com muita facilidade e em muito pouco tempo tanto a letra redonda como a manuscripta. Rio de Janeiro: Eduardo e Henrique Laemmert, 1862.

SEGUNDO LIVRO de leitura: editado pelos professores da Escola Gratuita São José. 9. ed. Petrópolis: Typographia das Vozes de Petrópolis, 1922.

SOUZA, R. F. Templos de civilização: a implantação da escola primária graduada no Estado de São Paulo (1890-1910). São Paulo: Unesp, 1998.

VIDAL, D. G. Livros por toda parte: o ensino ativo e a racionalização da leitura nos anos 1920 e 1930 no Brasil. In: ABREU, M. (org.). Leitura, história e história da leitura. Campinas: Mercado de Letras: Associação de Leitura do Brasil: Fapesp, 1999. p. 335-355.

\section{SOBRE A AUTORA}

Carlota Boto é professora titular da Faculdade de Educação da Universidade de São Paulo. É doutora em História Social pela FFLCH/USP. É pesquisadora produtividade PQ1 do CNPq. É autora dos livros $A$ escola do homem novo, Instruçáo pública e projeto civilizador, publicados pela Editora Unesp, $A$ escola primária como rito de passagem, publicado pela Imprensa da Universidade de Coimbra e A liturgia escolar na Idade Moderna, publicado pela Editora Papirus.

Recebido em 9 de agosto de 2018.

Aceito em 4 de fevereiro de 2019.

(C) 2019 Centro de Estudos Educação e Sociedade - CEDES Este é um artigo de acesso aberto distribuído nos termos de licença Creative Commons. 